\title{
THE EFFECT OF MAGNETIC AND LOCATOR ATTACHMENTS ON STRAIN AROUND IMPLANTS RETAINING MANDIBULAR OVERDENTURE: AN IN VITRO STUDY
}

\author{
Ahmed Fayyad*
}

\begin{abstract}
Objectives: This in-vitro strain gauge study was conducted to compare between magnetic and locator attachments regarding strain induced around two implants supporting a mandibular overdenture.

Methodology: The study was performed on acrylic models of a completely edentulous mandibular arch with two implants installed bilaterally at the canine areas. The strain induced around the implants was studied during unilateral and bilateral loading at the first molar area using a universal testing machine.
\end{abstract}

Results: The results of this study showed that there was no statistically significant difference between the two studied groups during unilateral loading with higher values in the locator attachment group while during bilateral loading there was a statistically significant difference between the two groups but with higher micro-strain values for the magnetic attachment group

Conclusion: Within the limitation of this in-vitro study, it could be conclude that the attachment type could have an effect on the amount of load that will be transmitted to the implants supporting an over denture. Clinical studies are required to evaluate the effect of type of attachment on periimplant crestal alveolar bone loss and correlate it with the results of the current study.

KEY WORDS: In-vitro study- Strain gauge analysis-magnetic attachment- locator attachmentOverdenture.

\section{INTRODUCTION}

More than twenty years ago, implants overdenture drawn a great attention to many clinicians due to its minimal invasiveness, simplicity and economic advantages. The type of attachment used to retain an overdenture to the implants has long been considered as an essential factor for implant success in terms of stresses transmitted to the implant during function. Previous research showed that stresses in the bone surrounding the implants were influenced by the type of attachments used. Animal experiments and clinical studies have shown that inappropriate loading causes excessive stress in the bone around

\footnotetext{
* Lecturer of Prosthodontics, Faculty of Dentistry, Cairo University.
} 
the implant that may result in bone resorption and implant failure ${ }^{(1-5)}$.

Recently, the locator attachments are widely used and now available from most implant manufacturing companies. The main advantages of these attachments are the self-aligning property and its dual (inner and outer) retention mechanism. Also one of its great advantages is that it can be used in patients who have limited inter-arch space to reduce denture base fracture thanks to their low profile. Moreover, Locators can compensate for angle corrections up to 40 degrees in some systems which is very important in non-parallel implant ${ }^{6-80}$.

Besides, locator attachment delivers greater patient satisfaction by giving a comfortable and stable prosthesis that provides better function. This particular attachment system is relatively new as compared to the bar, ball and magnetic attachments ${ }^{(9)}$.

The mode of retention of the Locator attachments is frictional contact, which arises from a dimensional misfit between the slightly oversized nylon male insert and the smaller diameter of the inner ring of the female abutment ${ }^{(10)}$.

Magnets had been successfully used as retentive aids in dentistry. The use of a magnet retained overdenture offered a simple reconstructive approach for complete denture retention ${ }^{(11,12)}$.

The main advantage of retaining an overdenture with magnets is the dissipation of the horizontal loads acting on the implants during function as well as its self-finding mechanism which is very useful in elderly edentulous patients ${ }^{(13-15)}$.

On the other hand, magnetic attachment has some drawbacks including the lack of long term durability due to their inevitable corrosion. Besides, patients with magnetic retained overdentures usually complained from a clicking noise during eating as the denture base shifted away from its foundation and then became reseated. Nowadays the companies are working on solving these problems ${ }^{(16)}$.

Strain gauge analysis provided both in vivo and in vitro measurements of strains induced under static or dynamic loading which is based on the fundamental concept that the electrical resistance of wire changed as a function of strain ${ }^{(17-21)}$. Many authors believed, that loads on dental implants should be measured using in vivo strain gauge method but unfortunately, there were many technical difficulties in connecting the strain gauges to the dento-alveolar region intraorally for many reasons ${ }^{(22,23)}$.

\section{Methodology}

This in-vitro study was conducted to compare between locator and magnetic attachment regarding strain induced around two implants supporting a mandibular overdenture. The study was performed on an acrylic models* representing a completely edentulous mandibular arch with two implants installed at the canine areas bilaterally. The ridge of the model has a diameter of $5 \mathrm{~mm}$ and length of 13 $\mathrm{mm}$ at the canine areas to accommodate a dummy implant of $3.7 \mathrm{~mm}$ diameter and $12 \mathrm{~mm}$ length (Figure 1). The sample size included 10 identical experimental models (5models/group). This sample size was calculated based on the results of previous study where the author used similar methodology.

For all models, two dummy implants ${ }^{* *}, 3.7 \mathrm{~mm}$ in diameter and $12 \mathrm{~mm}$ in length, were installed in the canine areas bilaterally. The canine areas were indicated by performing a trial set-up on one of the models to place the implants accurately in the planned area. A round bur was used to drill two holes at the previously marked sites. The drilled holes were enlarged gradually to accommodate the implants then followed by final enlargement using the final drill of the implant system. The implants

\footnotetext{
* Clear heat cured acrylic resin, Acrostone, Egypt.

** Dentaurum, Germany.
} 
were then tried into their holes, so that they flushed with the top of the ridge on the acrylic model. The implants were placed bilaterally in the canine regions parallel to each other and perpendicular to the residual ridge with the aid of a milling machine* to ensure parallelism. The implants were fixed to the models using flow mix of self-cured acrylic resin to simulate osseointegration. The previous steps were repeated for the 10 experimental models.

According to the type of the attachments, the experimental models were divided into two equal groups (5 models in each group). Group I included the models with locator attachment while group II included the models with the magnetic attachment. The attachments were tightened to the implants using their screwdriver at a torque of $35 \mathrm{NCm}$. Rubber base impression ** was made for one of the models and poured to obtain a stone cast on which trial denture base was constructed. Wax rim was then added and adjusted so that the occlusal plane height was built up to the level between the upper and middle third of retromolar pad. The conventional steps of complete denture construction were then followed till the overdenture was obtained. The finished denture was then duplicated 10 times for the 10 experimental models.

The acrylic resin of the model around each implant was reduced into a box shaped area using a long fissure bur mounted on straight hand piece leaving only $1 \mathrm{~mm}$ thickness of acrylic resin all around each implant. These surfaces were prepared to be flat and parallel to the long axis of the implants in all directions using a milling machine. All surfaces were smoothened with fine sandpaper before bonding of the strain gauges to avoid incremental apparent strain.

The strain gauges ${ }^{* * *}$ used in this study had a gauge length of $5 \mathrm{~mm}$, a resistance of $120.4 \pm 0.4$ $\Omega$ and a gauge factor of $2.09 \pm 1 \%$. For accurate monitoring of the effect of the applied load on the implants when using either magnetic or locator attachment, strain gauges were installed on the buccal, lingual, mesial and distal surfaces of the two implants. Since the used strain gauges were temperature-compensated for plastics, a dummy gauge was not used for temperature compensation (Stegaroiu et al., 2004) ${ }^{(24)}$.

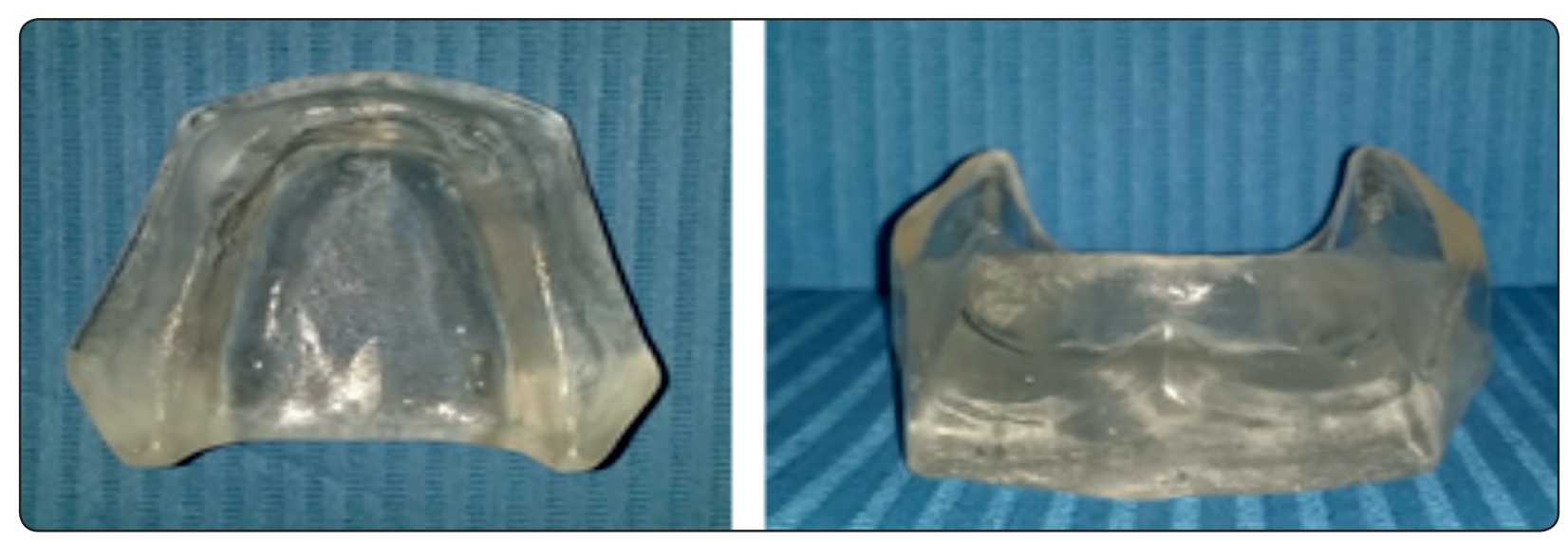

Fig. (1): The acrylic resin model

\footnotetext{
* Bego Bremer Goldschagerei Wihl. Herbst, Bremen, Germany.

** Zetaplus, Zermack, Italy.

*** Kyowa strain gauges, KFG-3-120-c1-11L1M2R, Japan.

$* * * *$ CC-33 strain gauge cement, Kyowa electronic instruments co., Japan.
} 


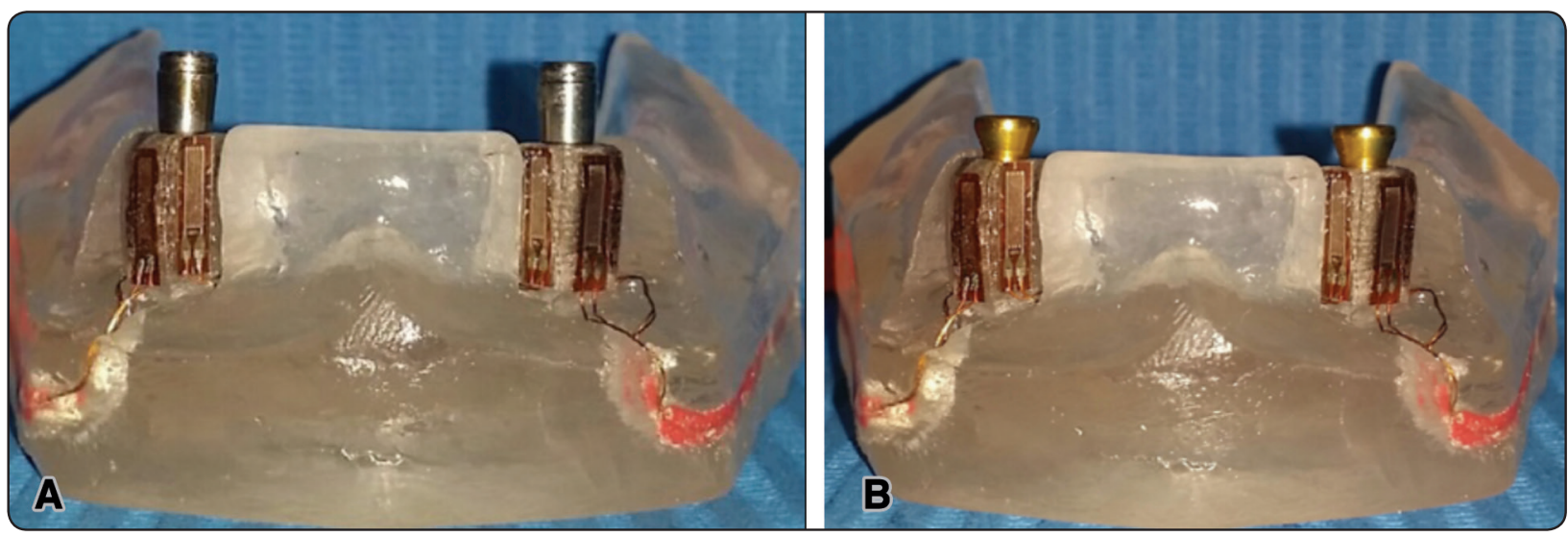

Fig. (2): The prepared model with the locator (A) and the magnetic (B) attachment after strain gauge installation

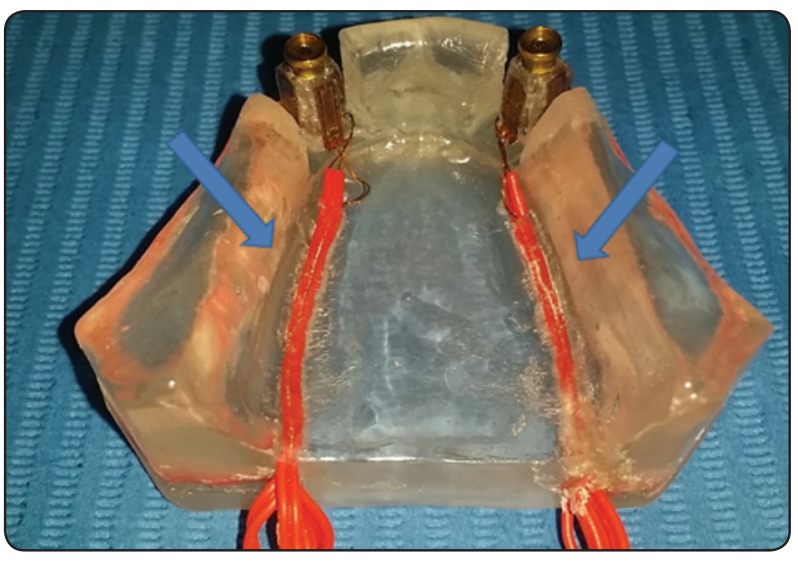

Fig. (3): Arrow pointing at the embedded wires in the prepared channels for wire protection.

\section{Installation of the strain gauges:}

Cyanoacrylate based adhesive $e^{* * * *}$ was used to bond the strain gauges to their corresponding surfaces around the implants (Figure 2). Light pressure was applied against the bonded gauges and the pressure was maintained for 5 minutes using a large ball burnisher. To ensure complete curing of the adhesive, the strain gauges were left for 24 hours. All wires were labeled, so that each wire of the active gauge has a label indicating the surface to be measured. The fine lead wires of the gauges were embedded in channels that where prepared specially for this purpose which was created in the base of the model to prevent their accidental dislodgement (Figure 3).

\section{Pick up procedures:}

The black processing cap of the locator attachment was attached to the locator abutment in the locator group while the magnetic keeper was placed over the magnetic abutment in the other group preparing for the pick up procedure.

Using a large fissure bur, the fitting surface of the denture was relieved at the area opposite to the abutments to create sufficient space for the acrylic resin during the pick up procedure.

A piece of rubber dam was placed around the attachment in order to prevent the acrylic resin from flowing over the prepared surface of the cast and the strain gauge which might affect the results. Acrylic resin was then mixed according to the

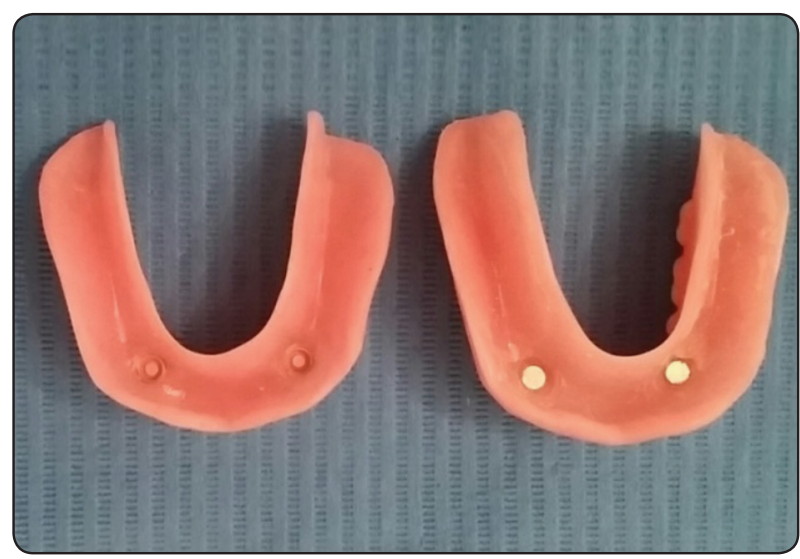

Fig. (4): The dentures after pick up a) Magnetic attachment. b) Locator attachments. 
manufacturer's instructions and placed in the fitting surface of the prosthesis, while in the dough stage. Finally after complete setting of the acrylic resin the prosthesis was removed and finished (Figure 4).

The black processing caps (in the locator group) were then removed and replaced with the pink nylon cap (light retention) using the locator press tool.

\section{Load application:}

The terminals of the lead wire of the strain gauges were connected to a multi-channel strain meter* (Figure 5) in order to calculate the microvoltage out-put which was converted into microstrain using special software (Kyowa PCD 300 A).

A digital universal testing machine ${ }^{* *}$ was used to apply a static vertical compressive load of $100 \mathrm{~N}$ for $15 \mathrm{~s}$ at a cross head speed of $0.5 \mathrm{~mm} / \mathrm{min}$ (Figure 6). This amount of load simulates a moderate level of biting force on an implant-retained overdenture, as was recommended by Porter et al $2002{ }^{(25)}$. Load was applied both bilaterally and unilaterally (Figure 7). For the unilateral loading, the point of load application was selected at the site of central fossa of the 1st molar on the loading side. A notch was made at the point of load application using a diamond bur to accommodate the tip of the loading pin for reproducibility and also to prevent slippage

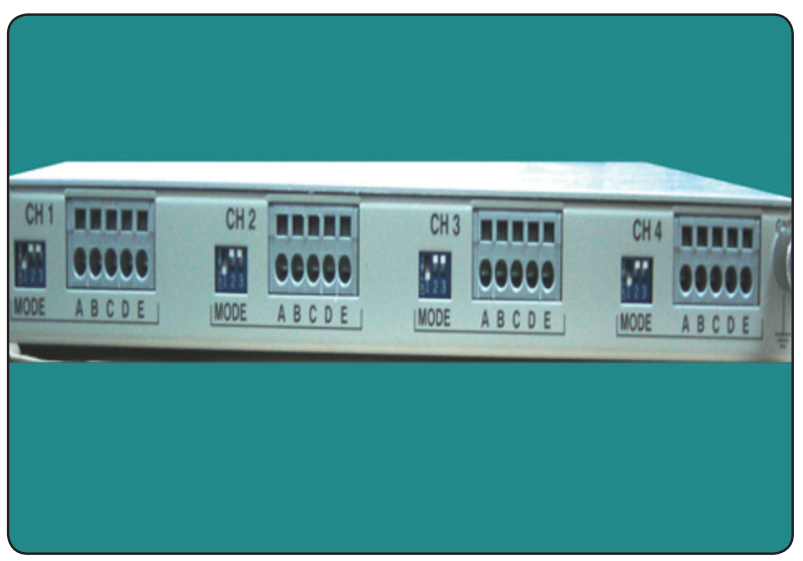

Fig. (5): The multi-channel strain meter.

\footnotetext{
* Model 8692, Tinsely precision instruments, Surrey, UK)

** Lloyd LR5K instrument, Fareham, Hampshire, UK)
}

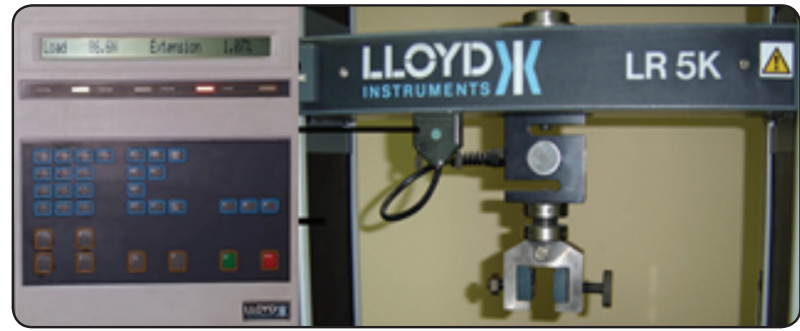

Fig. (6): The universal testing machine.

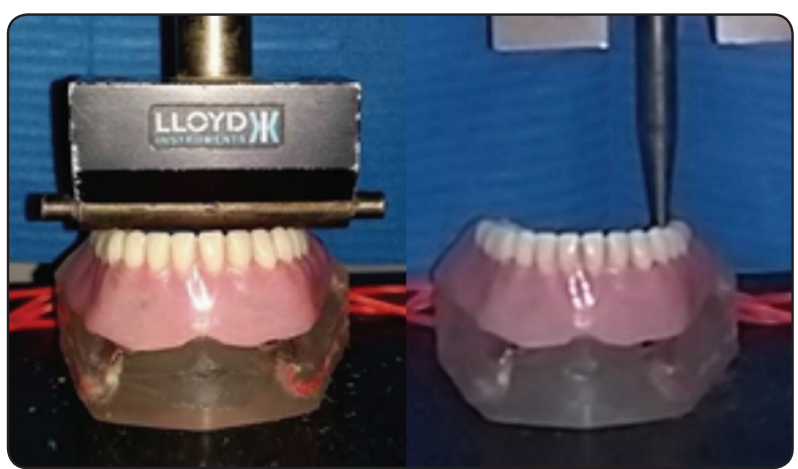

Fig. (7): (a) Bilateral loading. (b) Unilateral loading

of the pin as recommended by Elsayed et al. $2013{ }^{(26)}$. Strains were measured at the four periimplant surfaces (mesial, distal, buccal and lingual) at loading (left) and non-loading (right) sides. For each experimental overdenture, all measurements were repeated 5 times allowing at least $5 \mathrm{~min}$ between each reading for heat dissipation between each successive measurement. The mean recorded microstrain from the 5 measurements for the 10 models was subjected to statistical analysis.

\section{Statistical analysis}

The mean and standard deviation values were calculated for each group. Data were explored for normality using Kolmogorov-Smirnov and Shapiro-Wilk tests and showed parametric (normal) distribution. Independent sample-t test was used to compare between independent samples. The significance level was set at $\mathrm{P} \leq 0.05$. Statistical analysis was performed with IBM ${ }^{\circledR}$ SPSS ${ }^{\circledR}$ Statistics Version 20 for Windows. 


\section{RESULTS}

In the current study comparisons of the overall micro-strain values around the 2 implants were evaluated both in unilateral and bilateral loading where the load was applied on the first molar area during the bilateral and the unilateral loading tests.

\section{Unilateral loading (table 1, figure 8):}

For the locator attachment group there was no statistically significant difference in mean value of micro strain between the loaded and the unloaded side where $(\mathrm{p}=0.313)$. The lowest mean value of micro strain was found in the unloaded side $(170.00$ \pm 128.13 ) while the highest mean value of micro strain was found in the loaded side (310.00 \pm 219.73). The same was observed for the magnetic attachment group where $(\mathrm{p}=0.154)$ but the microstrain values were lower both for the loaded (95.00 $\pm 97.98)$ and the unloaded sides $(15.00 \pm 4.08)$

When comparing between the two groups at the loaded side it was found again that there was no statistically significant difference in mean values of micro strain between group I (locator attachment) and group II (magnetic attachment) where $(\mathrm{p}=0.124)$. The lowest mean value of micro strain was found in Group II (95.00 \pm 97.98) while the highest mean value of micro strain was found in group I (310.00 \pm 219.73). The same was observed when comparing between the two groups at unloaded side but with lower micro strain values.

\section{Bilateral loading (table 2 figure 9):}

- For Group I (Locator attachment) there was no statistically significant difference in mean value of micro strain between \{Right implant and $\{$ Left implant $\}$ where $(\mathrm{p}=0.101)$. The lowest mean value of micro strain was found in $\{$ Left implant\} $(22.50 \pm 15.55)$ while the highest mean value of micro strain was found in $\{$ Right implant\} $(45.00 \pm 17.32)$. The same microstrain pattern was observed in group II where $(\mathrm{p}=0.734)$.

- When comparing between the two groups at right implant it was found that there was a statistically significant difference in mean of micro strain between \{Group I\} and \{Group II\} where $(\mathrm{p}=0.040)$ where the lowest mean value of micro strain was found in the locator attachment group $(45.00 \pm 17.32)$ while the highest mean value of micro strain was found in the magnetic attachment group (118.75 \pm 53.60$)$.

- Similarly when comparing between the two groups at Left implant it was found that there was a statistically significant difference in mean of micro strain between both groups where $(\mathrm{p}=0.013)$. The lowest mean value of micro strain was found in the locator attachment group $(22.50 \pm 15.55)$ while the highest mean value of micro strain was found in the magnetic attachment group (106.25 \pm 45.35$)$.

TABLE (1): The mean, standard deviation (SD) values of micro strain of unilateral loading on first molar area of both groups.

\begin{tabular}{|c|c|c|c|c|c|}
\hline \multirow{3}{*}{ Variables } & \multicolumn{5}{|c|}{ Unilateral loading on first molar area } \\
\hline & \multicolumn{2}{|c|}{ Loaded side } & \multicolumn{2}{|c|}{ Unloaded side } & \multirow{2}{*}{$P$-value } \\
\hline & Mean & SD & Mean & SD & \\
\hline Group I (Locator attachment) & $310.00^{\mathrm{aA}}$ & 219.73 & $170.00^{\mathrm{aA}}$ & 128.13 & $0.313 \mathrm{~ns}$ \\
\hline Group II (Magnetic attachment) & $95.00^{\mathrm{aA}}$ & 97.98 & $15.00^{\mathrm{aA}}$ & 4.08 & $0.154 n s$ \\
\hline$P$-value & \multicolumn{2}{|c|}{$0.124 \mathrm{~ns}$} & \multicolumn{2}{|c|}{$0.052 n s$} & \\
\hline
\end{tabular}

Means with different small letters in the same column indicate statistically significance difference; means with different capital letters in the same row indicate statistically significance difference. *; significant $(p<0.05)$ ns; non-significant $(p>0.05)$ 
TABLE (2): The mean, standard deviation (SD) values of micro strain of bilateral loading on first molar area of both groups.

\begin{tabular}{|c|c|c|c|c|c|}
\hline \multirow{3}{*}{ Variables } & \multicolumn{5}{|c|}{ Bilateral loading on first molar area } \\
\hline & \multicolumn{2}{|c|}{ Right implant } & \multicolumn{2}{|c|}{ Left implant } & \multirow{2}{*}{$P$-value } \\
\hline & Mean & SD & Mean & SD & \\
\hline Group I (Locator attachment) & $45.00^{\mathrm{aA}}$ & 17.32 & $22.50^{\mathrm{aA}}$ & 15.55 & $0.101 n s$ \\
\hline Group II (Magnetic attachment) & $118.75^{\mathrm{bA}}$ & 53.60 & $106.25^{\mathrm{bA}}$ & 45.35 & $0.734 \mathrm{~ns}$ \\
\hline P-value & \multicolumn{2}{|c|}{$0.040 *$} & \multicolumn{2}{|c|}{$0.013 *$} & \\
\hline
\end{tabular}

Means with different small letters in the same column indicate statistically significance difference, means with different capital letters in the same row indicate statistically significance difference. *; significant $(p<0.05) \quad n s$; non-significant $(p>0.05)$

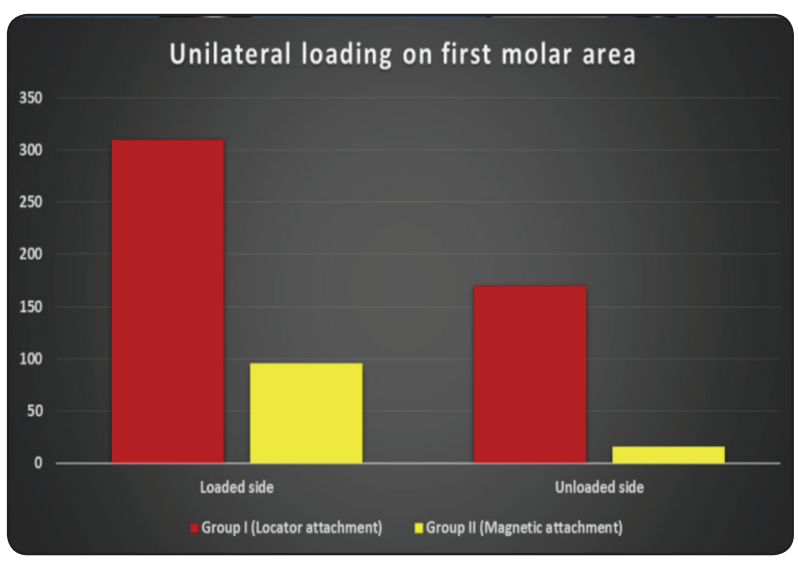

Fig. (8): Bar chart representing means of micro strain of unilateral loading on first molar area in both groups

\section{DISCUSSION}

In the current study, the gauges were bonded on the prepared buccal, lingual, mesial and distal surfaces around the implants because the alveolar crest in these areas are the most important areas where the stresses are usually initiated and thus bone loss is expected and therefore overloading may occur from the compression of the cortical bone around the alveolar crest ${ }^{(27)}$.

The load was applied both unilaterally and bilaterally to simulate all the patients chewing patterns, as most of the patients had a preferable chewing side (unilateral) while other few patients prefer to chew on both sides (bilateral). It is well

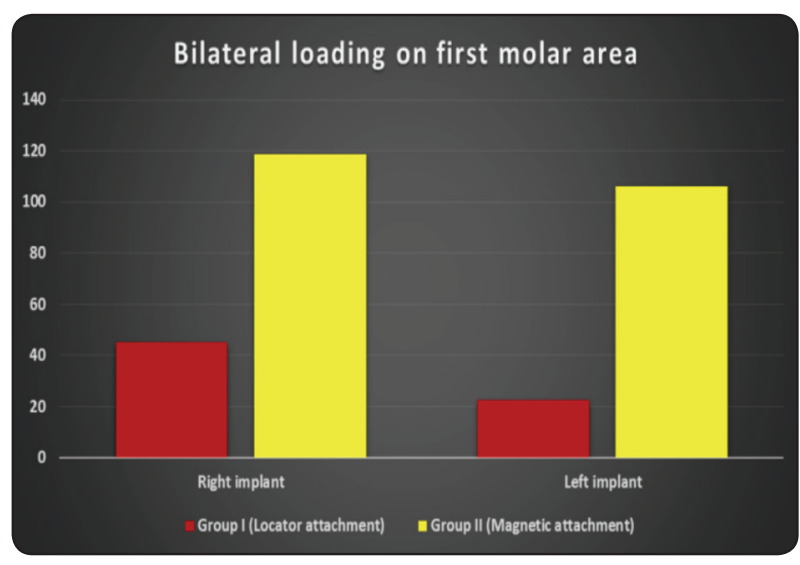

Fig. (9): Bar chart representing means of micro strain of bilateral loading on first molar area in both groups

known that the first molar area is the area where the maximum occlusal forces are exerted where there is maximum contraction of the elevator muscles, so this area was chosen for load application during our study ${ }^{(28)}$.

Although there was no statistical significant difference between both groups during unilateral loading, it was observed that the micro strain values around both implants was higher in the locator attachment group than the magnetic attachment one; this might be attributed to the fact that the male nylon flange of the locator attachments had a double frictional flange in its male nylon element which provides limited hinge movement. Therefore this 
attachment was reported to transmit higher stresses to the implants during posterior loading than other types ${ }^{(29,30)}$.

When comparing the loaded and the unloaded sides in both groups, it was found that the loaded side received higher load than the unloaded one, this was observed in many other invitro studies ${ }^{(31-33)}$. This may be attributed to the fact that the implants at the loaded side acted as a fulcrum around which the prosthesis rotated.

The unloaded implant in the locater attachment group received higher load than the unloaded implant in the magnetic attachment group, this may be again due to the double frictional flange of the nylon insert of the locator attachment which prevent total disengagement of the female part, the thing that increased the peri-implant strain at the non loaded side. While in the other group disengagement of the magnetic attachment is much easier.

When comparing between the two groups during bilateral loading, it was found that the implants in the magnetic attachment group received higher micro-strain values than the implants in the locator attachment group. This may be attributed to the nylon insert of the female part of the locator attachment which may act as a cushion that reduces the load over the implant. On the other hand the magnetic attachment does not have this cushion effect, as it is metal to metal contact, the thing that concentrated the load around the implants.

\section{CONCLUSION}

Within the limitation of this in-vitro study, it could be conclude that the attachment type could have an effect on the amount of load that will be transmitted to the implants supporting an over denture. Clinical studies are required to evaluate the effect of the type of attachment on peri-implant crestal alveolar bone loss and correlate it with the results of the current study.

\section{REFERENCES}

1. Pierrisnard L, Renouard F, Renault P, Barquins M. Influence of implant length and bicortical anchorage on implant stress distribution. Clin Implant Dent Relat Res 2003; 5: 254 .

2. Adell R, Lekholm U, Rockler B, Branemark PI. A 15-year study of osseointegrated implants in the treatment of the edentulous jaw. Int J Oral Surg 1981; 10: 387

3. Block MS, Gardiner D, Kent JN, Misiek DJ, Finger IM, Guerra L. Hydroxyapatite-coated cylindrical implants in the posterior mandible: 10-year observations. Int J Oral Maxillofac Implants 1996; 11: 626.

4. Tawil G, Aboujaoude N, Younan R. Influence of prosthetic parameters on the survival and complication rates of short implants. Int J Oral Maxillofac Implants 2006; 21: 275.

5. Holmgren EP, Seckinger RJ, Kilgren LM, Mante F Evaluating parameters of osseointegrated dental implants using finite element analysis - a two-dimensional comparative study examining the effects of implant diameter, implant shape, and load direction. J Oral Implantol 1998; 24: 80 .

6. Elsyad MA, Errabti HM, Mustafa AZ. Mandibular denture base deformation with Locator and ball attachments of implant-retained overdentures. J Prosthodont 2015; 25:656.

7. Evtimovska E, Masri R, Driscoll CF, Romberg E. The change in retentive values of locator attachments and hader clips over time. J Prosthodont 2009; 18: 479.

8. Srinivasan M, Schimmel M, Badoud I, Ammann P, Herrmann FR, Muller F. Influence of implant angulation and cyclic dislodging on the retentive force of two different overdenture attachments - an in vitro study. Clin Oral Implants Res 2016; 27: 604.

9. Mahajan N, Thakkur RK. Overdenture locator attachments for atrophic mandible. Contemp Clin Dent. 2013;4:509.

10. Alsabeeha N, Atieh M, Swain MV, Payne AG. Attachment systems for mandibular single-implant overdentures: an in vitro retention force investigation on different designs. Int J Prosthodont 2010; 23: 160

11. Jackson, T.R.: The application of rare earth magnetic retention to osseointegrated implants. Int. J. Oral Maxillofac. Implants. 1986 1: 81.

12. Walmsley, A.D. and Frame, J.W.: Implant-supported overdentures. The Birmingham experience. J. Dent. 1997;25: 543. 
13. Budtz-Jorgensen, E.: Prosthodontics for the elderly. Diagnosis and treatment. Quintessence publishing Co., Inc. Illinois. 1999: 222.

14. Coca, I., Lotsmann, U. and Prisender, K.: A clinical followup study of magnetically-retained overdentures (Dyna system). Eur. J. Prosthodont. Res. Dent. 2002; 10: 73.

15. Watzek, G.: Endosseous implants: Scientific and clinical aspects. Quintessence publishing Co, Inc. 1997; 340.

16. Davis, D.M.: Implant-supported overdentures: The king experience. J. Dent. 1997; 25: 533.

17. Smedberg, J.I., Nilner, K., Rangert, B., Svensson, S.A. and Glantz, P.O.: The influence of superstructure connection on implant preload: A methodological and clinical study. Clin. Oral Implants Res. 1996; 7: 55.

18. Assif, D., Marshak, B., and Horowitz, A.: Analysis of load transfer and stress distribution of an implant-supported fixed partial denture. J. Prosthet. Dent. 1996; 75: 285.

19. Uysal, H., Iplikcioglu, H., Avic, M., Bilino, O.G. and Kural, O.: An experimental analysis of the stresses on the implant in an implant tooth supported prosthesis: A technical note. Int. J. Oral and Maxillofac. Impl. 1997; 12: 118.

20. Batenburg, R.H.K., Meijer, H.J.A., Raghoebar, G.M. and Vissink,A.: Treatment concept for mandibular Overdenture supported by endosseous implant: A literature review. Int. J. of Oral and Maxillofac. Implants. 1998; 13: 539.

21. Brosh,T.,Pilo, R., and Sudai, D.: The influence of abutment angulations on strains and stresses along the bone/ implant interface: comparison between two experimental techniques. J. Prosthet. Dent. 1998; 79: 328.

22. Ormianer, Z., Brosh, T., Laufer, B.Z. and Shifman, A.: Strains recording in a combined tooth-implant restoration: An in vivo study. Implant Dent. 2005; 14: 58.

23. Glantz, P.O., Rangert, B. and Svensson, A.: On clinical loading of osseointegrated implants. A methodological and clinical study. Clin. Oral Impl. Res. 1993; 4: 99.

24. Stegaroiu, R., Khraisat, A., Nomura, S. and Miyakawa,
O.: Influence of superstructure material on strain around an implant under two loading conditions: A technical investigation Int. J. Oral Maxillofac Implants. 2004; 19: 735 .

25. Porter JA, Jr, Petropoulos VC, Brunski JB. Comparison of load distribution for implant overdenture attachments. Int J Oral Maxillofac Implants 2002; 17: 651.

26. Elsyad MA, Elsaadawy MG, Abdou AM, Habib AA. Effect of different implant positions on strain developed around four implants supporting a mandibular overdenture with rigid telescopic copings. Quintessence Int 2013; 44: 679.

27. Kong L, Sun Y, Hu K, Li D, Hou R, Yang J, Liu B. Bivariate evaluation of cylinder implant diameter and length: a three dimensional finite element analysis. J Prosthodont 2008; 17: 286.

28. Sadowsky SJ, Caputo AA. Stress transfer of four mandibular implant overdenture cantilever designs. J Prosthet Dent 2004; 92: 328.

29. Celik G, Uludag B. Photoelastic stress analysis of various retention mechanisms on 3-implant-retained mandibular overdentures. J Prosthet Dent 2007; 97: 229.

30. Chikunov I, Doan P, Vahidi F. Implant-retained partial overdenture with resilient attachments. J Prosthodont 2008; 17: 141 .

31. Tokuhisa M, Matsushita Y, Koyano K. In vitro study of a mandibular implant overdenture retained with ball, magnet, or bar attachments: comparison of load transfer and denture stability. Int J Prosthodont 2003; 16: 128.

32. Celik G, Uludag B. Photoelastic stress analysis of various retention mechanisms on 3-implant-retained mandibular overdentures. J Prosthet Dent 2007; 97: 229.

33. Hong HR, Pae A, Kim Y, Paek J, Kim HS, Kwon KR. Effect of implant position, angulation, and attachment height on periimplant bone stress associated with mandibular twoimplant overdentures: a finite element analysis. Int J Oral Maxillofac Implants 2012; 27: 69. 